\title{
Utility of Ocular Motility Tests in Orbital Floor Fractures with Muscle Entrapment That is Not Detected on Computed Tomography
}

\author{
Raffaele Migliorini' \\ Anna Maria Comberiati ${ }^{\prime}$ \\ Fernanda Pacella ${ }^{1}{ }^{\prime}$ \\ Anna Rosy Longo' \\ Daniela Messineo (iD ${ }^{2}$ \\ Edoardo Trovato Battagliola (iD) ${ }^{1}$ \\ Mariaelena Malvasi (iD) \\ Elena Pacella ${ }^{1}{ }^{\prime}$ \\ Loredana Arrico (iD ${ }^{\prime}$ \\ 'Department of Sense Organs, University \\ Sapienza, Rome, Italy; ${ }^{2}$ Department of \\ Radiology, Oncology, and \\ Anatomopathological, University \\ Sapienza, Rome, Italy
}

Correspondence: Elena Pacella

Department of Sense Organs, University Sapienza, Policlinico Umberto I, Viale del

Policlinico I55, Rome, 00I6I, Italy

Tel +39336783409

Email elena.pacella@uniromal.it
Purpose: Determine the usefulness of ocular motility testing to detect the presence of muscle entrapment.

Materials and Methods: Cross-sectional study of patients with symptoms of diplopia secondary to facial trauma. Inclusion criteria: age between 20 and 80 years; symptoms of diplopia following facial trauma; presence of orbital floor fracture confirmed radiologically; presence of muscle entrapment confirmed at the time of surgery; best-corrected visual acuity of 0.6 or more. Exclusion criteria: muscle entrapment visible on computed tomography; candidate for immediate surgical correction; prior history of strabismus surgery. Outcome measures: Abnormal Head Position (AHP), Hirschberg Corneal Reflexes (CR), Cover/ Uncover and Alternating Cover Test, Hertel exophthalmometry, Near Point of Convergence (NPC), Kestenbaum Limbus test, Red Filter test, and Hess screen test.

Results: Forty-six subjects ( 38 males, 8 females, mean age $27 \pm 3.3$ SD years). Preoperative assessment: forty-six (100\%) reported diplopia on the Red Filter test and showed some degree of abnormality on the Hess Screen test. Forty-two (91\%) showed AHP. Fortyone $(89 \%)$ had exophthalmometry values that differed $2 \mathrm{~mm}$ or more between the two eyes and insufficient NPC. Thirty-two (69.6\%) showed deficits of $3 \mathrm{~mm}$ or more on the Kestenbaum Limbus test. Sixteen (35\%) had abnormal Hirschberg corneal reflexes. Eleven (24\%) demonstrated constant or intermittent strabismus.

Conclusion: Ocular motility testing can differentiate non-invasively, pre-operatively, and costeffectively the presence of muscle entrapment even when this is not visible on computed tomography.

Keywords: orbital blow-out fractures, orbital floor fracture, ocular motility, trauma, delayed surgical repair, muscle entrapment, traumatic diplopia

\section{Introduction}

Patients with orbital floor fractures (OFF) generally present with periorbital ecchymosis, diplopia, and enophthalmos. ${ }^{1-3}$ Diplopia is a sign of ocular dysmotility. This can be caused by soft tissue edema and hemorrhage, which generally require observation, or by other etiologies, such as muscle entrapment, muscle and nerve damage, that require surgical repair. ${ }^{4-8}$ Immediate surgical repair is only indicated when obvious signs of muscular entrapment or damage are present. These include: presence of muscle incarceration confirmed with computed tomography, fracture size greater than $50 \%$ of the orbital floor, presence of the ocular-cardiac reflex, hypoglobus or asymmetry in eyeball position, and obvious facial disfigurement. ${ }^{3,9-13}$ In all other instances, most practitioners will prefer 
to observe and wait for edema to resorb. If diplopia persists beyond several days, the clinical suspicion for muscular entrapment or damage remains high, even when these are not visible radiologically. In these patients, surgical repair is generally indicated and is best performed between the 2 nd and the 5th week post-trauma. It is not recommendable to wait beyond the 5th week to avoid complications, such as muscle atrophy or fat redistribution. ${ }^{14-16}$ Computed tomography is routinely obtained in trauma patients to confirm the presence of a fracture. However, it has modest soft tissue sensitivity and only detects about $70 \%$ of cases of ocular muscle entrapment. MRI offers higher resolutions but is not readily available in some centers and is surely much more expensive. ${ }^{17}$ Forced ductions can be performed to rule out the diagnosis of muscular entrapment but are very uncomfortable and can trigger a vagal response and lead to syncope. In all doubtful cases, the presence of muscle entrapment is confirmed at the time of surgery.

Ocular motility assessment is not routinely performed in patients who present to the emergency room with complaints of diplopia following facial trauma. In this study, authors explore the usefulness of ocular motility testing to detect the presence of muscle entrapment when it is not visible on computed tomography.

\section{Materials and Methods}

This cross-sectional study was conducted on the medical records of patients with persistent diplopia following facial trauma and no radiological signs of muscle entrapment. These patients presented to the Emergency Room of the Policlinico Umberto I hospital following facial trauma. This study was approved by the Ethics board of the University of Rome "La Sapienza" and adheres to the tenets of Helsinki. All subjects were informed about the purpose of the study and provided written consent upon enrollment.

\section{Inclusion Criteria}

- Age between 20 and 80 years

- Presence of new-onset diplopia following facial trauma

- Presence of orbital floor fracture confirmed with computed tomography

- Presence of muscle entrapment confirmed at the time of surgery

- Best-corrected visual acuity (BCVA) of 0.6 or more on Snellen chart or 70-letter or more on the Early Treatment Diabetic Retinopathy Study (ETDRS) chart (Chart "R", Precision Vision" ${ }^{\mathrm{TM}}$, La Salle, IL, USA) at $4 \mathrm{~m}$ distance.

\section{Exclusion Criteria}

- Muscle entrapment visible on computed tomography scan on initial assessment

- Other indications for immediate surgical repair, that include bone fracture size greater than $50 \%$ of the orbital floor, hypoglobus or asymmetry in eyeball position, presence of the ocular-cardiac reflex, or obvious facial disfigurement.

- History of prior strabismus surgery

All these patients reported symptoms of diplopia following facial trauma. The initial assessment in the ER included the following tests. All tests were performed by the same practitioner to avoid interpersonal variability.

- Abnormal Head Position (AHP): in the setting of ocular motility restriction, some subjects will assume abnormal head positions to achieve binocular fusion. This test grades head position abnormalities on a numerical scale from 0 to $4(0=$ AHP absent, $1=$ mild AHP, $2=$ moderate AHP, 3 = moderate to severe AHP, $4=$ severe AHP). "Mild" indicates that AHP is present occasionally or head tilt is less than 10 degrees from the normal head position relative to the midline. "Moderate" indicates that APH is present half of the time or head tilt is between 10 and 15 degrees relative to the midline. "Moderate to severe" indicates that APH is present most of the time and head tilt is between 10 and 15 degrees relative to the midline. "Severe" indicates that APH is present all the time or head tilt is greater than 20 degrees relative to the midline.

- Hirschberg Corneal Reflexes Test (RC): measures the off-deviation of the corneal reflection in the deviated eye when patient fixates at near (33 centimeters) and at distance (5 meters).

- Cover/Uncover or Alternating Cover Test (CT): differentiates between latent and intermittent deviation. It is performed when the patient fixates both at near (33 centimeters) and at distance (5 meters).

- Exophthalmometry: performed in both elevation and depression. Values of both eyes are compared. In the healthy population, the difference between the two eyes generally does not exceed $2 \mathrm{~mm} .{ }^{18}$ Measurements were taken with the Hertel exophthalmometer.

- Near Point of Convergence (NPC): this was measured with the RAF rule. The reason why this test was included is because superior and inferior rectus muscles have 
secondary adduction function. Involvement of either of these muscles can cause a proximal convergence deficit.

- Limbus Kestenbaum test: reference values in the healthy population are 5-7 $\mathrm{mm}$ on elevation, and 9-10 $\mathrm{mm}$ on depression, adduction, and abduction.

- Hess Screen test: to quantify the elevation and/or depression deficit on a numerical scale from 0 to $3.0=$ no motility restriction, $1=$ mild deficit $\left(5^{\circ}\right.$ or less of motility restriction), $2=$ moderate deficit (between $5^{\circ}$ and $10^{\circ}$ of motility restriction), $3=$ severe deficit $\left(10^{\circ}\right.$ or more of motility restriction). A mechanical restriction presents with ipsilateral hypofunction of the affected muscle in the diagnostic gaze position, associated with motility deficit in the opposite gaze position.

- Red filter test: to assess diplopia in all directions of gaze. This was performed with the patient fixating both at near $(33 \mathrm{~cm})$ and at distance $(5 \mathrm{~m})$.

- Computed tomography: scans were acquired with highresolution CT with volumetric acquisition (Toshiba Aquilion CT, 16 channels). Acquisition parameters were individualized for each patient and ranged from 120 to $100 \mathrm{kV}, 100$ to $50 \mathrm{~mA}$, pitch $1,0.5$ seconds per rotation and subsequent MPR (multiplanar) reconstructions.

The presence of bone fracture was confirmed radiologically. Orbital sections did not show evidence of muscle entrapment. Based on these results, patients were not candidate for immediate surgical repair, and it was elected to observe. However, the persistence of diplopia symptoms beyond 10 days following trauma raised the clinical suspicion of muscle entrapment.
A new ocular motility assessment confirmed the persistence of ocular dysmotility. At this point, the surgical team agreed to proceed to surgery. All patients received surgical repair between the 18th and 22nd day following trauma. The presence of muscle entrapment was confirmed at the time of surgery in all patients.

\section{Statistical Analysis}

The statistical analysis was carried out calculating frequency distribution and contingency tables. The chi-square test was used to assess differences between groups. Two categories were created for the variable Hess screen test (severe versus non-severe abnormality). Moreover, a score test was created using the following variables:

- Near point of convergence: (Insufficient $=1$ versus normal $=0$ )

- Abnormal head position (moderate or severe $=1$ versus mild or absent $=0$ )

- Exophthalmometry $($ Abnormal $=1$ versus Normal $=0)$

- Kestenbaum limbus test $($ deficit $=1$ versus Normal $=0)$

The analysis was carried out using SPSS 25.0 for Windows. The statistical significance was set at $\mathrm{p}<0.05$.

\section{Results}

Figure 1 presents the demographics characteristics of the study sample. Table 1 presents the results of all orthoptic tests.

Sixteen subjects (35\%) showed abnormal Hirschberg corneal reflexes. Of these, six patients showed micro-strabismus

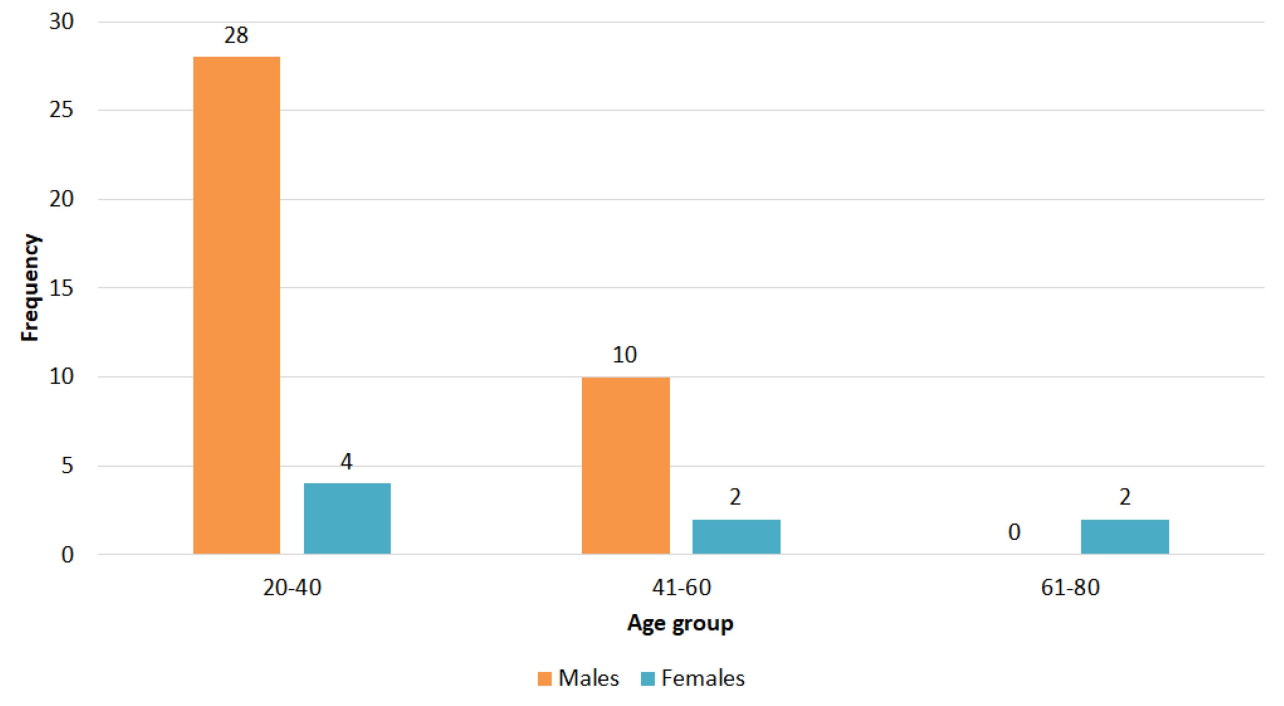

Figure I Frequency distribution of participants grouped by age and gender. 
Table I Characteristics of Participants

\begin{tabular}{|l|c|}
\hline Variables & N. (\%) or Mean (SD) \\
\hline Gender & $8(17.4 \%)$ \\
Females & $38(82.6 \%)$ \\
\hline Ages & 27 years (3.3) \\
\hline Diplopia & $46(100 \%)$ \\
Worse on elevation & $33(72 \%)$ \\
Worse on depression & $13(28 \%)$ \\
\hline Abnormal Head Posture & $42(91 \%)$ \\
Mild & $16(35 \%)$ \\
Moderate & $12(26 \%)$ \\
Moderate/Severe & $10(22 \%)$ \\
Severe & $4(9 \%)$ \\
\hline Exophthalmometry & \\
Within normal limits & $5(11 \%)$ \\
Outside of normal limits & $41(89 \%)$ \\
\hline Near point of convergence & $14(30 \%)$ \\
Normal & $14(30 \%)$ \\
Insufficient & $5(11 \%)$ \\
\hline Kestembaum limbus test & $41(89 \%)$ \\
Normal & \\
Elevation deficit & $(40 \%)$ \\
Depression deficit & \\
\hline
\end{tabular}

on the Irvine test, two showed vertical strabismus, four showed intermittent vertical strabismus, and two showed intermittent horizontal strabismus, and two exhibited a combination of horizontal and vertical strabismus of intermittent type. Thirty subjects (65\%) had normal Hirschberg corneal reflexes, maintained fixation with the contralateral uninvolved eye, and showed tropias and phorias on the Cover/Uncover test, the Alternating Cover test, and the Maddox Cross Test. Twelve patients (26\%) showed deviation incomitance.

Forty-one subjects (89\%) showed exophthalmometry values that differed $2 \mathrm{~mm}$ or more between the two eyes. These patients had an absolute difference of 1-10 mm between the two eyes in either elevation or depression. Abnormal exophthalmometry was associated with abnormal NPC and/or intermittent strabismus.

On the Kestenbaum Limbus test, fourteen subjects (30.4\%) showed normal muscle excursions, while the remaining thirty-two $(69.6 \%)$ showed motility restrictions greater than $3 \mathrm{~mm}$ from normal reference values (eighteen showed elevation deficits, fourteen subjects showed depression deficits).
The Red Filter test revealed diplopia in all (100\%) participants. Thirty-two subjects $(69.6 \%)$ reported diplopia mostly in upward gaze, while the remaining fourteen $(30.4 \%)$ mostly in downward gaze.

All subjects showed some degree of abnormality on the Hess Screen test. Twenty-four subjects (52\%) with an abnormal Hess Screen Test also showed a motility deficit greater than $3 \mathrm{~mm}$ and abnormal exophthalmometry values.

Table 2 reports the correlation of the results of the Hess screen test (categorized as non-severe abnormalities or severe abnormalities) and the results of the other orthoptic tests. A severe abnormality on the Hess Screen test has a statistically-significant association with the results of AHP ( $\mathrm{p}$ value $<0.001)$.

Figure 2 shows the results of the score analysis. As visible on the chart, $87 \%$ of all patients had a score of 2 or higher. This means that patients had at least two abnormal results from all performed tests.

\section{Discussion}

Scientific studies on ocular dysmotility in patients with orbital fractures are still scarce. Jank et al (1999) first defined the criteria for conservative treatment: absence of soft tissue entrapment in the fracture site, absence of significant orbital floor displacement, absence of ocular motility disorders and diplopia. ${ }^{19-24}$ Laurentjoye et al compared Hess Screen test results from 47 patients with orbital floor fractures. Authors concluded that ocular motility testing should be included in the initial work-up of patients with a fractured orbit and symptoms of diplopia. ${ }^{23}$ Nishida et al found that if the involved eye moves at least 10 or 20 degrees on a 15- or 30-degree Hess chart respectively, spontaneous motility recovery can be expected, even though it might take more than 4 weeks. ${ }^{21}$ Ceylan et al run a study with 39 patients with symptoms of diplopia on primary gaze following facial trauma author found that diplopia resolved spontaneously in $30.7 \%$ of participants only. The remaining twenty-three (58.9\%) required surgery. Yab et al described radiologically how orbital tissue edema modifies eyeball position in the days following trauma. Authors concluded that Hess Screen testing is best performed between the 5 th and the 10th day post-trauma. At this point in time, the measured motility deficit becomes is most reflective of the permanent residual deficit. ${ }^{4}$

In this study, authors confirmed that ocular motility testing can become a valuable component of the initial 
Table 2 Correlation Between the Results of the Hess Screen Test (Grouped as Severe or Non-Severe Abnormalities) and the Other Variables

\begin{tabular}{|c|c|c|c|}
\hline \multirow[t]{2}{*}{ Variables } & \multicolumn{2}{|c|}{ Hess Screen Test Result } & \multirow[t]{2}{*}{$P$ value } \\
\hline & Non-Severe Abnormality & Severe Abnormality & \\
\hline \multicolumn{4}{|l|}{ Kestenbaum test } \\
\hline Depression deficit & II (28.1\%) & $3(42.9 \%)$ & 0.164 \\
\hline Elevation deficit & 14 (35.9\%) & $4(57.1 \%)$ & \\
\hline Normal & 14 (35.9\%) & $0(0 \%)$ & \\
\hline \multicolumn{4}{|c|}{ Abnormal Head Position } \\
\hline Absent & 4 & 0 & \\
\hline Mild & 16 & 0 & \\
\hline Moderate & $\mathrm{II}$ & I & $<0.001$ \\
\hline Moderate/Severe & 8 & 2 & \\
\hline Severe & 0 & 4 & \\
\hline \multicolumn{4}{|l|}{ Exophthalmometry } \\
\hline Abnormal & $34(87.2 \%)$ & 7 (100\%) & 0.420 \\
\hline Normal & $5(12,8 \%)$ & $0(0 \%)$ & \\
\hline \multicolumn{4}{|c|}{ Near point of convergence } \\
\hline Insufficient & $34(87.2 \%)$ & $7(100 \%)$ & 0.420 \\
\hline Normal & $5(12,8 \%)$ & $0(0 \%)$ & \\
\hline
\end{tabular}

work-up of patients with orbital floor fracture associated with symptoms of diplopia. In fact, authors found that motility testing can detect the presence of muscle entrapment, even when this is not readily identifiable on computed tomography.
Based on the results obtained, the severity of AHP is correlated with the severity on the Hess screen test. In addition, using the system score illustrated in the Methods section, $87 \%$ of all subjects had a sum score of 2 or higher. One likely limitation of this study is represented by the small sample size.

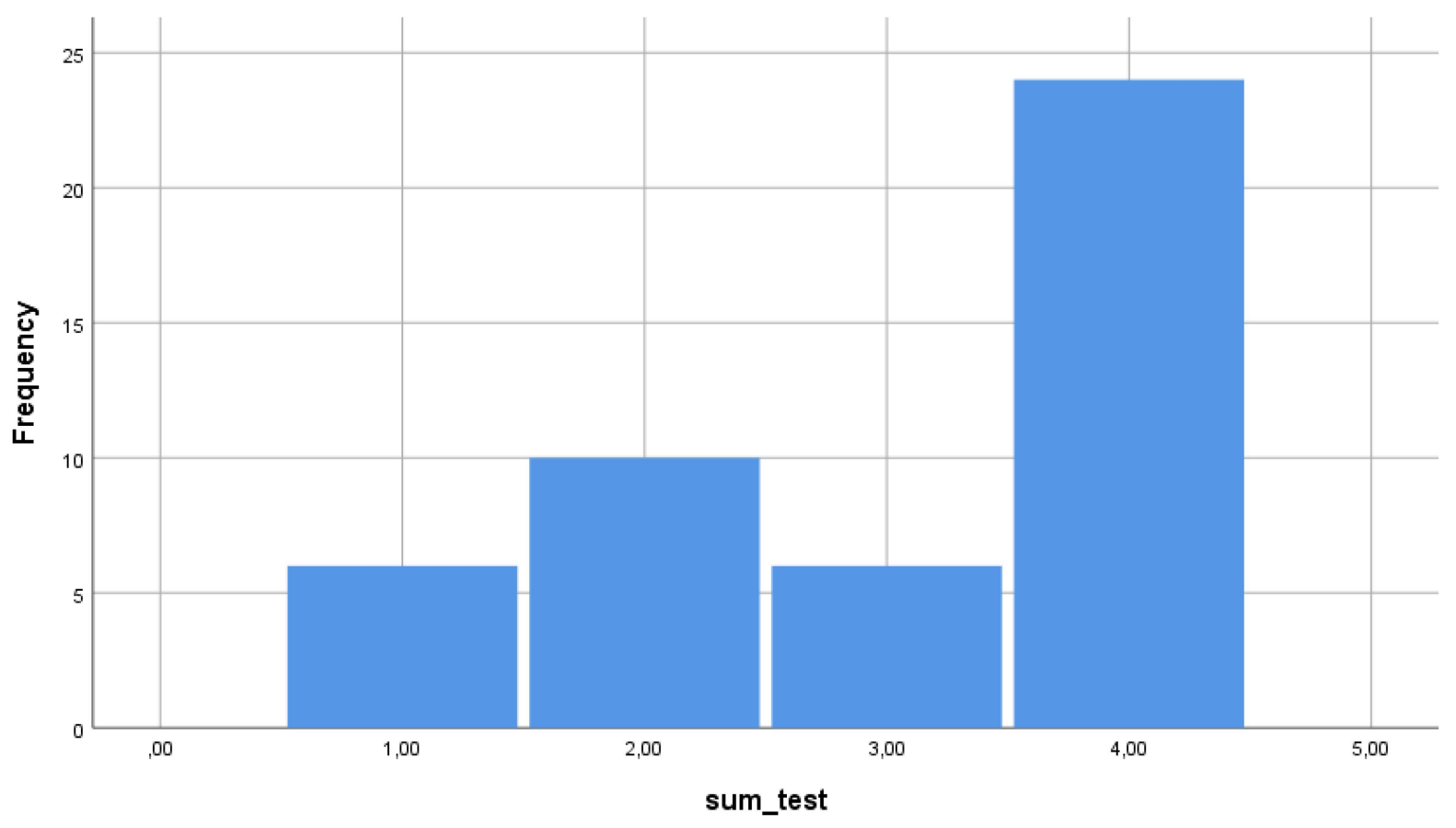

Figure 2 Results of the sum test. 
The analysis of results of the present study suggests that ocular motility testing in patients with orbital floor fractures help to confirm the presence of muscle entrapment, even when not visible on computed tomography. The presence of soft tissue entrapment is generally an indication for surgery. Surgical repair should be performed within two to five weeks from trauma to avoid muscle atrophy and fat redistribution within the orbital cone.

\section{Conclusion}

In agreement with data from literature, not all patients with a fractured orbit and diplopia require immediate surgical intervention. In some cases, it is preferrable to observe and follow-up. ${ }^{24}$ If symptoms of diplopia persist, surgical repair might be indicated even when muscle entrapment is not visible on computed tomography. ${ }^{19,20}$ Orthoptic tests help to confirm the diagnosis of muscle entrapment. Authors are continuing the current work with a larger sample size and a control group to bring stronger evidence of the results.

\section{Acknowledgments}

We thank Professor Giuseppe La Torre (Department of Public Health and Infectious Diseases, La Sapienza University of Rome) for his precious contribution to the statistical analysis of this research.

\section{Funding}

There is no funding to report.

\section{Disclosure}

The authors report no conflicts of interest.

\section{References}

1. Chi MJ, Ku M, Shin KH, Baek S. An analysis of 733 surgically treated blowout fractures. Ophthalmologica. 2010;224:167-175. doi:10.1159/ 000238932

2. Grob S, Yonkers M, Tao J. Orbital fracture repair. Semin Plast Surg. 2017;31:31-39. doi:10.1055/s-0037-1598191

3. Gart MS, Gosain AK. Evidence-based medicine: orbital floor fractures. Plast Reconstr Surg. 2014;134:1345-1355.

4. Yab K, Tajima S, Ohba S. Displacements of eyeball in orbital blowout fractures. Plast Reconstr Surg. 1997;100:1409-1417. doi:10.1097/ 00006534-199711000-00005

5. Alinasab B, Borstedt K-J, Rudström R, et al. New algorithm for the management of orbital blowout fracture based on prospective study. Craniomaxillofac Trauma Reconstr. 2018;11:285-295. doi:10.1055/ s-0038-1641714

6. Homer N, Huggins A, Durairaj VD. Contemporary management of orbital blowout fractures. Curr Opin Otolaryngol Head Neck Surg. 2019;27:310-316. doi:10.1097/MOO.0000000000000550
7. Nagasao T, Miyamoto J, Jiang H, Tamaki T, Kaneko T. Interaction of hydraulic and buckling mechanisms in blowout fractures. Ann Plast Surg. 2010;64:471-476. doi:10.1097/SAP.0b013e3181a6c288

8. Steinegger K, De Haller R, Courvoisier D, Scolozzi P. Orthoptic sequelae following conservative management of pure blowout orbital fractures: anecdotal or clinically relevant? J Craniofac Surg. 2015;26: e433-7. doi:10.1097/SCS.0000000000001886

9. Cole P, Boyd V, Banerji S, Hollier LH Jr. Comprehensive management of orbital fractures. Plast Reconstr Surg. 2007;120:57S-63S. doi:10.1097/01.prs.0000260752.20481.b4

10. Cramer LM, Tooze FM, Lerman S. Blowout fractures of the orbit. $\mathrm{Br}$ J Plast Surg. 1965;18:171-179. doi:10.1016/S0007-1226(65)80022-4

11. Su Y, Shen Q, Bi X, Lin M, Fan X. Delayed surgical treatment of orbital trapdoor fracture in paediatric patients. $\mathrm{Br} J$ Ophthalmol. 2019;103:523-526. doi:10.1136/bjophthalmol-2018-311954

12. Woernley TC, Wright TL, Lam DN, Jundt JS. Oculocardiac reflex in an orbital fracture without entrapment. J Oral Maxillofac Surg. 2017;75:1716-1721. doi:10.1016/j.joms.2017.03.014

13. Theunissen CMMC, Corcoran MS, van Dael CMLK. [Oculocardiac reflex associated with orbital floor fracture; the value of a reliable patient history]. Ned Tijdschr Geneeskd. 2015;160:A9641. Dutch.

14. Arrico L, Migliorini R, Bianchini D, Salducci M, Collini S, Malagola R. Ocular motility alterations in orbital fractures: pre-post evaluation in maxillofacial surgical treatment. G Chir. 2018;39:363-367.

15. Dal Canto AJ, Linberg JV. Comparison of orbital fracture repair performed within 14 days versus 15 to 29 days after trauma. Ophthal Plast Reconstr Surg. 2008;24:437-443. doi:10.1097/ IOP.0b013e31818aac9b

16. Gosau M, Schöneich M, Draenert FG, Ettl T, Driemel O, Reichert TE. Retrospective analysis of orbital floor fractures-complications, outcome, and review of literature. Clin Oral Investig. 2011;15:305-313. doi:10.1007/s00784-010-0385-y

17. Lin KY, Ngai P, Echegoyen JC, Tao JP. Imaging in orbital trauma. Saudi $J \quad$ Ophthalmol. 2012;26:427-432. doi:10.1016/j. sjopt.2012.08.002

18. de Juan E Jr, Hurley DP, Sapira JD. Racial differences in normal values of proptosis. Arch Intern Med. 1980;140:1230-1231. doi:10.1001/archinte.1980.00330200106028

19. Alinasab B, Qureshi AR, Stjärne P. Prospective study on ocular motility limitation due to orbital muscle entrapment or impingement associated with orbital wall fracture. Injury. 2017;48:1408-1416. doi:10.1016/j.injury.2017.04.039

20. Clauser L, Galiè M, Pagliaro F, Tieghi R. Posttraumatic enophthalmos: etiology, principles of reconstruction, and correction. J Craniofac Surg. 2008;19:351-359. doi:10.1097/ SCS.0b013e3180534361

21. Nishida Y, Hayashi O, Miyake T, et al. Quantitative evaluation of ocular motility in blow-out fractures for selection of non surgically managed cases. Am J Ophthalmol. 2004;137:777-779. doi:10.1016/ S0002-9394(03)00972-3

22. Ceylan OM, Uysal Y, Mutlu FM, Tuncer K, Altinsoy HI. Management of diplopia in patients with blowout fractures. Indian J Ophthalmol. 2011;59:461-464. doi:10.4103/0301-4738.86313

23. Laurentjoye M, Bondaz M, Majoufre-Lefebvre C, Huslin V, Caix P, Ricard AS. [When should an orthoptic evaluation be prescribed in the management of orbital floor fracture? A prospective study of 47 fractures]. Rev Stomatol Chir Maxillofac Chir Orale. 2014;115:274-278. French. doi:10.1016/j.revsto.2014.07.005

24. Jank S, Schuchter B, Strobl H, et al. [Post-traumatic ocular motility in orbital floor fractures]. Mund Kiefer Gesichtschir. 2003;7:19-24. German. doi:10.1007/s10006-002-0439-7 


\section{Publish your work in this journal}

Clinical Ophthalmology is an international, peer-reviewed journal covering all subspecialties within ophthalmology. Key topics include: Optometry; Visual science; Pharmacology and drug therapy in eye diseases; Basic Sciences; Primary and Secondary eye care; Patient Safety and Quality of Care Improvements. This journal is indexed on PubMed
Central and CAS, and is the official journal of The Society of Clinical Ophthalmology (SCO). The manuscript management system is completely online and includes a very quick and fair peer-review system, which is all easy to use. Visit http://www.dovepress.com/ testimonials.php to read real quotes from published authors.

Submit your manuscript here: https://www.dovepress.com/clinical-ophthalmology-journal 